研 究

\title{
Process for Production of Ti Sintered Compacts Using the Injection Molding Method
}

\author{
Hidefumi Nakamura, Tokihiro Shimura and Kouei Nakabayashi \\ Metal Powder Dept. Manufacturing Division No.2, Hachinohe Works, Pacific Metals Co., Ltd. Hachinohe, Aomori 031-8617.
}

Received March 29, 1999

\begin{abstract}
SYNOPSIS
Pure Ti, which is used in the field of Metal Injection Molding (MIM), can be used to produce parts with complicated shapes. But, since oxidation, nitrogen and carbonization are generated during the debinding-sintering process, the mechanical properties of the sintered material cannot achieve the same level as those of the ingot material. Accordingly, we have studied the debinding and sintering methods by using various binder systems. This paper reports on the mechanical properties required by customers ( $0.2 \%$ proof stress of $216 \mathrm{MPa}$ or more, tensile strength of 343 to 510 $\mathrm{MPa}$, and elongation of $10 \%$ or more) and the development of the parts production process.
\end{abstract}

KEY WORDS

metal injection molding, titanium, binder, debinding, sintering, mechanical properties

\section{Introdution}

Ti-based material is excellent, because it provides light weight, high strength and high corrosion resistance. However, this material has low machinability, so it is difficult to utilize it for the production of parts with complicated shapes. Therefore, we have been conducting production testing of Ti-based parts by utilizing the injection molding method, which can be used to produce complicatedly shaped and near-net shaped parts.

Usually, we have primarily produced injection molded parts utilizing stainless-based materials, but had never utilized material like Ti, which has such problems as it easily oxidizes, nitrides and carbonizes during the debindingsintering process and it is difficult to increase its sintered density. Oxygen, nitrogen and carbon are interstitial atoms that have significant influence on mechanical properties. In particular, oxygen content, which increases with organicbased binder, furnace contamination, etc., is considered to adversely influence the mechanical properties of sintered compacts.

Accordingly, we report on the research about our production process utilizing pure Ti powder as the raw material and the utilization of injection molding to obtain the sintered compacts that have good mechanical properties and low oxygen content.

\section{Experimental Method}

\subsection{Raw material powder}

The raw material powder utilized is TILOP- 45 gas atomized powder, which is a high-purity Ti powder with a mean particle size of $23.81 \mu \mathrm{m}$ and is made by Sumitomo Sitix of Amagasaki, INC. The chemical components and powder properties of this powder are listed in Table 1. The oxygen content of this powder is 0.13 mass $\%$ and is lower than the oxygen content ( 0.4 to 0.5 mass $\%$ ) of conventional fine Ti powder.

\subsection{Binder}

Four types of the organic-based binders A, B, C and D are utilized for solvent extraction. The factor causing oxidation and carbonization is the binder. Binder is composed of polymer-based and wax-based components, which contain oxygen. Thus, in this research, we selected the binder with the lowest oxygen content. With general binders, if debinding is performed in an inert gas atmosphere, they are completely decomposed at the temperature range from 773 to $873 \mathrm{~K}$. To prevent the carbon containting in the binder from remaining in the sintered compact, we selected a polymer that could be decomposed completely during heat debinding at a temperature lower than $773 \mathrm{~K}$. The components of these binders are shown in Table 2. The components of these binders are, as shown in Table 2, resin polypropylene (P.P.) and wax-based components (paraffin wax, carnauba wax, etc.), and the ratio and composition is different each. The difference between 
Table 1 Chemical composition and properties of Ti powder. (TILOP-45 made by SUMITOMO SITIX OF AMAGASAKI,INC.)

\begin{tabular}{|c|c|c|c|c|c|c|c|c|}
\hline \multicolumn{6}{|c|}{ Chemical composition (mass.\%) } & \multirow{2}{*}{$\begin{array}{c}\text { Mean } \\
\text { particle size } \\
(\mu \mathrm{m})\end{array}$} & \multirow{2}{*}{$\begin{array}{l}\text { Specific } \\
\text { surface } \\
\left(\mathrm{cm}^{2} / \mathrm{cm}^{3}\right)\end{array}$} & \multirow{2}{*}{$\begin{array}{c}T / D \\
\left(\mathrm{~g} / \mathrm{cm}^{3}\right)\end{array}$} \\
\hline $\mathrm{Fe}$ & $\mathrm{O}$ & $\mathrm{C}$ & $\mathrm{N}$ & $\mathrm{H}$ & $\mathrm{Ti}$ & & & \\
\hline 0.0067 & 0.13 & 0.016 & 0.015 & 0.010 & Bal. & 23.81 & 2,842 & 2.85 \\
\hline
\end{tabular}

Table 2 Composition of binders for solvent extraction.

\begin{tabular}{|l|c|c|c|c|}
\hline & A & B & C & D \\
\hline P.P. (mass\%) (Polypropylene) & 40 & 30 & 40 & 35 \\
\hline Wax (mass\%) (paraffin, carnauba etc.) & 60 & 70 & 60 & 65 \\
\hline
\end{tabular}

$A$ and $C$ is that, although the ratio of polypropylene to wax is the same, the ratio of paraffin wax to carnauba wax are changed.

\subsection{Kneading}

Table 3 shows the kneading ratio of Ti powder to organicbased binder. Using a pressure-type kneader, the feedstocks were made by cooling and milling after pressure kneading at $447 \mathrm{~K}$ for $3.6 \mathrm{ks}$.

\subsection{Molding}

For molding, we used a screw type molding machine (made by NISSSEI PLASTIC INDUSTRIAL CO., LTD.) that had a clamping pressure of 40 tons to make a JIS-type

tensile test specimen with a length of $115 \mathrm{~mm}$, a width of $10 \mathrm{~mm}$ and a thickness of $6 \mathrm{~mm}$.

\subsection{Debinding-Sintering}

As the method for debinding the obtained compact, we adopted both solvent extraction and thermal debinding, and

Table 3 Ratio of kneading binders (Pressure-type kneader)

\begin{tabular}{|l|c|}
\hline Powder & 70 vol\% \\
\hline Binder & $30 \mathrm{vol} \%$ \\
\hline
\end{tabular}

Table 4 Binder extraction rate after solvent extraction.

\begin{tabular}{|l|c|c|c|c|}
\hline Binder type & A & B & C & D \\
\hline $\begin{array}{l}\text { Rate of wax in binder } \\
\text { (mass\%) }\end{array}$ & 60 & 70 & 60 & 65 \\
\hline $\begin{array}{l}\text { Extraction rate of binder } \\
\text { (mass\%) }\end{array}$ & $57 \sim 60$ & $52 \sim 55$ & $43 \sim 46$ & $58 \sim 61$ \\
\hline $\begin{array}{l}\text { Extraction rate of wax } \\
\text { (mass\%) }\end{array}$ & $95 \sim 100$ & $75 \sim 78$ & $72 \sim 77$ & $89 \sim 94$ \\
\hline
\end{tabular}


performed extraction of the wax-based binder at $313 \mathrm{~K}$ for $18 \mathrm{ks}$ in the solvent, then sintered the compact after heat debinding in a vacuum sintering furnace.

We performed debinding from room temperature to 773 $\mathrm{K}$ in an argon atmosphere to prevent oxidation and nitriding in the vacuum sintering furnace. Then, after sintering at $5.4 \mathrm{~K}$ in a high vacuum from 1 to $2 \times 10^{-2} \mathrm{~Pa}$ at the temperature range between 1423 and $1503 \mathrm{~K}$, the compact was cooled in an argon pressure atmosphere. We, then, analyzed the various mechanical properties, relative density and chemical components of the sintered specimens, and observed therir microstructures.

\section{Results of Experiment and Examination}

3.1 Examination of binder composition

Table 4 shows the extraction ratio of binder and wax after solvent extraction. The extraction ratio of binder is 43 to $61 \%$ and, among the 4 types, $\mathrm{D}$ binder has the highest extraction ratio, followed by A, B and C in order. Next, A binder shows the highest extraction ratio of wax, followed by $\mathrm{D}, \mathrm{B}$ and $\mathrm{C}$ in order. From these results, it was shown that one of the wax-based binders was difficult to dissolve into solvent, and the others could easily dissolved into solvent

3.2 Relationship between binder composition and mechanical properties of sintered compacts

We performed heat debinding after solvent extraction, after then performed vacuum-sintering at $1443 \mathrm{~K}$ for 5.4 $\mathrm{ks}$. The results of the mechanical properties $(0.2 \%$ proof stress, tensile strength, elongation)and the chemical analysis (oxygen, carbon, nitrogen) of the sintered compacts are shown in Figure 1.

The $0.2 \%$ proof stress is within the range from 360 to $382 \mathrm{MPa}$ and there is almost no difference in $0.2 \%$ proof stress among the binders. The tensile strength is within the range from 458 to $504 \mathrm{MPa}, \mathrm{B}$ binder shows the lowest values.

The elongation depends on the binder composition, that is, $\mathrm{A}$ binder shows a high value of $19 \%$, but $\mathrm{C}$ binder shows a very low value of only $6 \%$. The chemical analysis gives low value of 0.22 mass $\%$ in oxygen content, 0.04 mass $\%$ in carbon content and 0.017 mass $\%$ in nitrogen content for the sintered speccimen that were made by using $\mathrm{A}$ binder which provides the best elongation, while $\mathrm{C}$ binder which provides the lowest elongation, showed high values of 0.29 mass \% in oxygen conten and 0.13 mass $\%$ in carbon content. Therefore, it should be considered that the oxygen and carbon contents affect the elongation of the sintered compacts.
One of the causes of higher oxygen content is considered to be that some of the wax-based components in the binder contain oxygen as a composition. Thus, the decomposition of the binder during the debinding process may generate oxidation of Ti powder. Also, the cause of higher carbon content is cosidered to be that the carbon in the residual binder may be brought as the residual carbon in the sintering
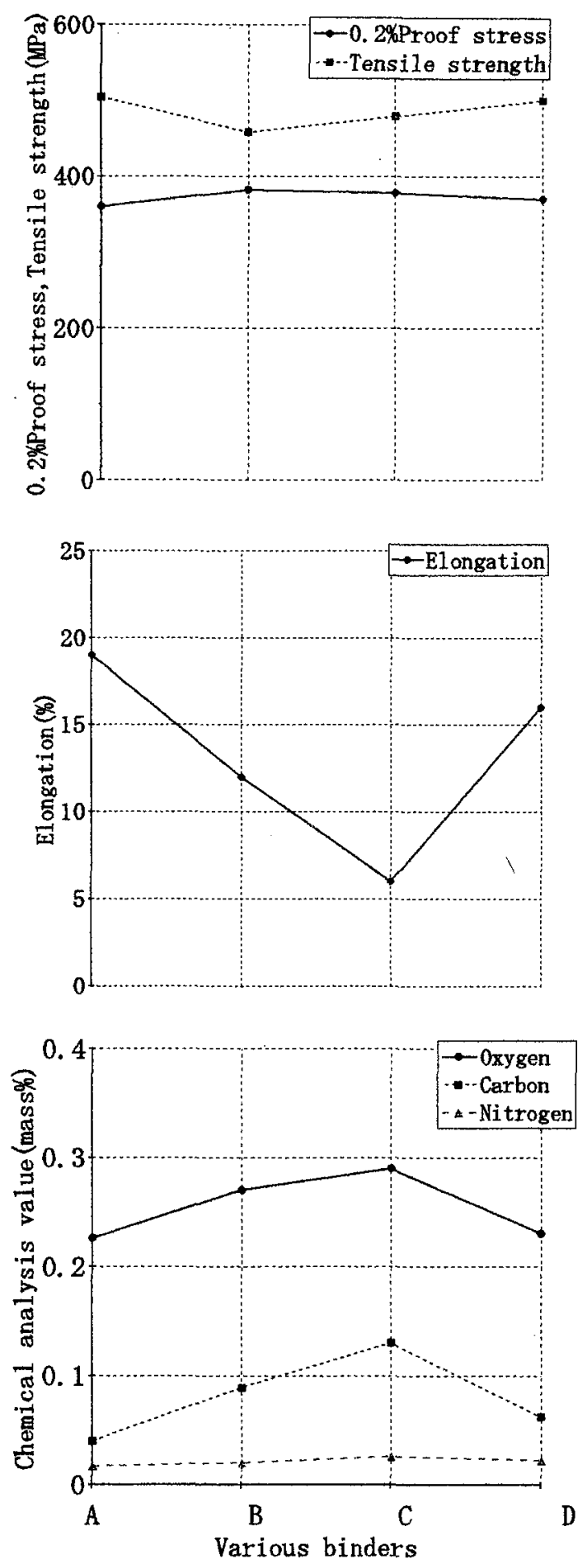

Fig.1 Relationship between types of binder and various properties of sintered compacts. 
process because of low binder extraction ratio.

3.3 Relationship between sintering temperatures and mechanical properties of the sintered compacts

Among four types of the binder, the compact of A binder, which sintered at $1443 \mathrm{~K}$ for $5.4 \mathrm{ks}$ showed the best mechanical properties. The relationship between the sintering temperature and the mechanical properties was examined by sintering at the temperatures of 1423,1443 , 1463,1483 and $1503 \mathrm{~K}$ for the sintering time of $5.4 \mathrm{ks}$. Figure 2 shows the relationship between the sintering temperatures and the mechanical properties of the sintered compacts.

Concerning $0.2 \%$ proof stress and tensile strength, there is little influence of sintering temperature. The elongation gets better as the sintering temperature increases and reaches the maximum of $21.5 \%$ at $1463 \mathrm{~K}$ but, above this sintering temperature, it suddenly decreases to 4 or $5 \%$. The relative density increases with increasing the sintering temperature.

To find out the cause of this sudden lowering of elongation when the sintering temperature rises above 1463 $\mathrm{K}$, we conducted chemical analysis. The oxygen content was around 0.2 mass $\%$, the carbon content was 0.4 mass $\%$ and the nitrogen content around 0.002 mass $\%$. These are not values that would affect elongation of the sintered compact. In previous academic presentations ${ }^{1-2)}$, it was reported that the oxygen content of the sintered compact increases as the sintering temperature increases, and at 0.3 mass $\%$ or more, the elongation suddenly decreases.

Next, we used EPMA to analyze the oxygen, carbon, nitrogen and other various elements ( $\mathrm{Si}, \mathrm{Mg}, \mathrm{Al}, \mathrm{Fe}$, etc.), but there was no difference between the sintered compacts of high and low elongation. Then, we prepare two test specimens; one sintered at $1463 \mathrm{~K}$, which provided high elongation and one sintered at $1503 \mathrm{~K}$, which provided the lowest elongation. They were cut off at the depths of 1,2 and $3 \mathrm{~mm}$ from the surface and analyzed them. Figure 3 shows the results of element analysis. As shown in this figure, the oxygen content is around 0.22 mass $\%$, and $\mathrm{Al}$ was detected and its content is around 0.012 mass $\%$, but there is no difference in content between the surface and the inner part. Fe content is 0.08 mass \% near the surface and around 0.07 mass \% in the inner part. Si content is a high value of 0.03 mass $\%$ at the surface, but in the inner part it decreased to 0.012 mass $\%$. These values were not influenced by the sintering temperature. However, concerning $\mathrm{Cr}$, in the test specimen that had high elongation, its content was 0.018 mass $\%$ at the surface and 0.013 mass $\%$ in the inner part, but in the test specimen having poor elongation $\mathrm{Cr}$ content was 0.025 mass \% at the surface and
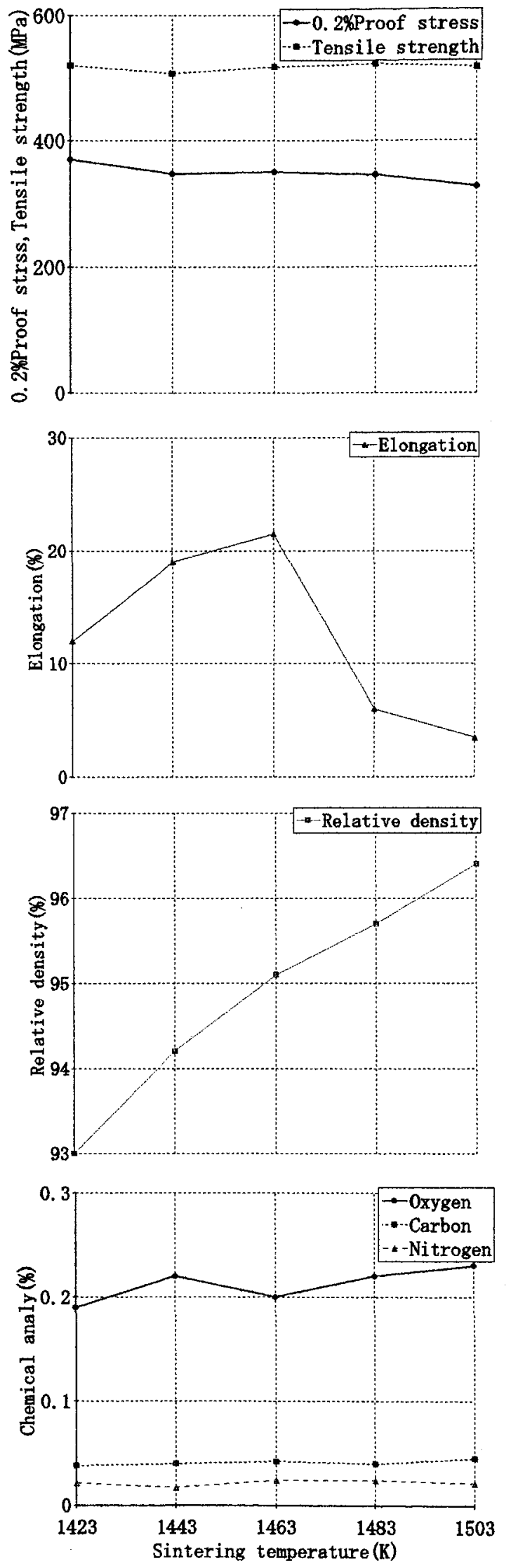

Fig.2 Relationships between sintering temperature and mechanical properties ( $0.2 \%$ Proof stress, Tensile strength. Elongation) relative density and chemical analysis values (oxygen, carbon. nitrogen). 

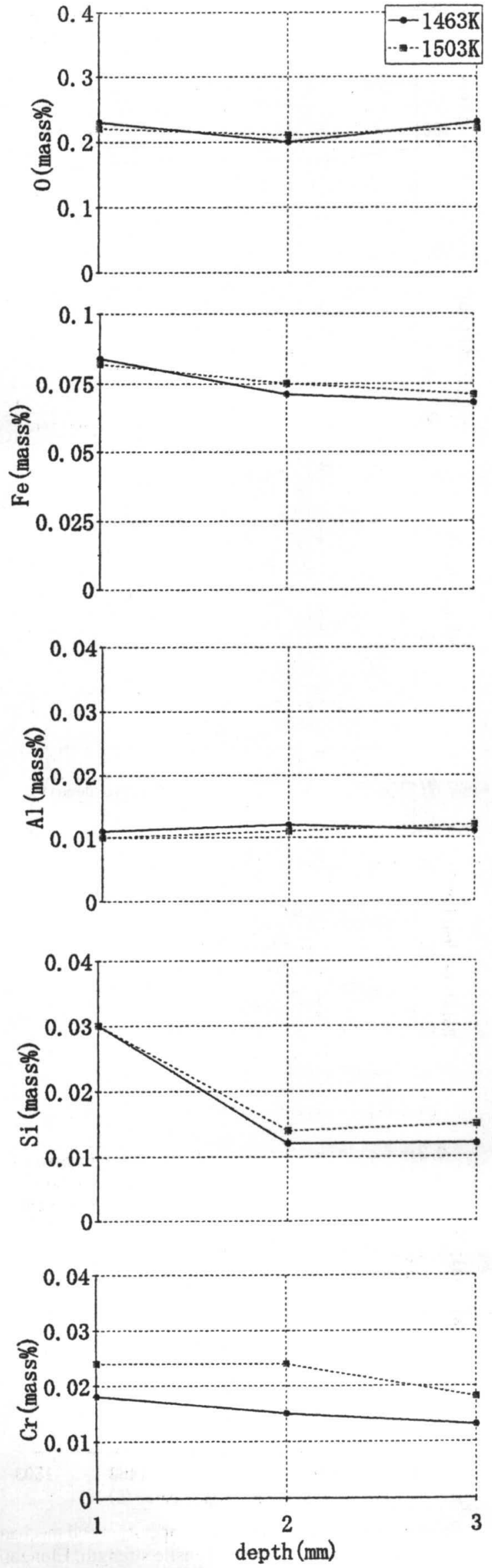

Fig.3 Chemical analysis values at various depth from upper surface of the sample $(\mathrm{O}, \mathrm{Fe}, \mathrm{Al}, \mathrm{Si}, \mathrm{Cr})$.
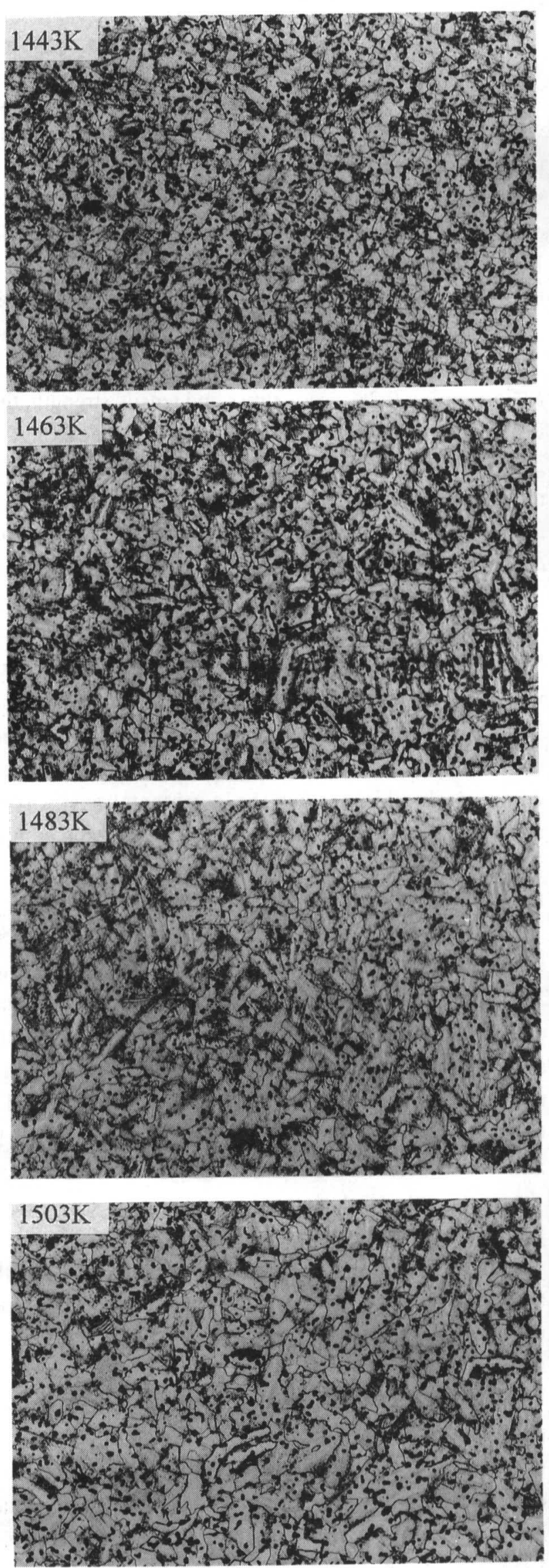

Fig.4 Microstructures of 'l'i sintered compacts $(\times 100)$. 
0.019 mass \% in the inner part. Thus, there is a difference in $\mathrm{Cr}$ content between two specimens.

Concerning $\mathrm{Cr}$ penetration, our company's vacuum sintering furnace is usually used for stainless steel in argon atmoshere. In this case, $\mathrm{Cr}$ in the surface layer easily evaporates, so $\mathrm{Cr}$ sticks to the furnace and causes furnace contamination. If the same vacuum sintering furnace is used to sinter $\mathrm{Ti}$ in a high vacuum, the $\mathrm{Cr}$ that has stuck to the furnace may evaporate, and penetrate into the Ti sintered compact. From this analysis the penetration of $\mathrm{Cr}$ was considered to be the factor that causes the sudden decrease in elongation in Ti sintered compacts above than a certain sintering temperature.

3.4 Microstructures of the sintered compacts

Fig. 4 shows the microstructures of the compacts sintered at various temperatures. Comparing the microstructure at $1423 \mathrm{~K}$ to that at $1503 \mathrm{~K}$, the sintered density of the compact sintered at $1503 \mathrm{~K}$ is higher and closer, and the size of crystal grains of the compact sintered at $1503 \mathrm{~K}$ is larger than that of the compact sintered at $1423 \mathrm{~K}$.

3.5 Comparison with reactive material

Table 5 shows a comparison of the mechanical properties among reactive materials (Type JIS3), customer required property values and MIM products. The mechanical properties of MIM products of pure Ti satisfy those of the standards for Type JIS3 reactive material. In addition, customer required property values for $0.2 \%$ proof stress and tensile strength meet the required values for Type JIS2 standards. Thus, it can be said the sintered compact satisfies all requirements.

Table 5 Comparison of mechanical properties of reactive materials (Type JIS3), customer required property values and MIM products.

\begin{tabular}{|c|c|c|c|c|c|c|}
\hline & $\begin{array}{c}\mathrm{O} \\
(\mathrm{mass} \%)\end{array}$ & $\begin{array}{c}\mathrm{C} \\
(\mathrm{mass} \%)\end{array}$ & $\begin{array}{c}\mathrm{N} \\
(\mathrm{mass} \%)\end{array}$ & $\begin{array}{c}0.2 \% \text { Proof } \\
\text { stress } \\
(\mathrm{MPa})\end{array}$ & $\begin{array}{c}\text { Tensile } \\
\text { strength } \\
(\mathrm{MPa})\end{array}$ & $\begin{array}{c}\text { Elongation } \\
(\%)\end{array}$ \\
\hline JIS3 & $\leqq 0.3$ & - & $\leqq 0.007$ & $\geqq 343$ & $451 \sim 617$ & $\geqq 18$ \\
\hline Customer required & - & - & - & $\geqq 216$ & $343 \sim 510$ & $\geqq 10$ \\
\hline MIM products & 0.226 & 0.04 & 0.0017 & 360 & 504 & 19.0 \\
\hline
\end{tabular}

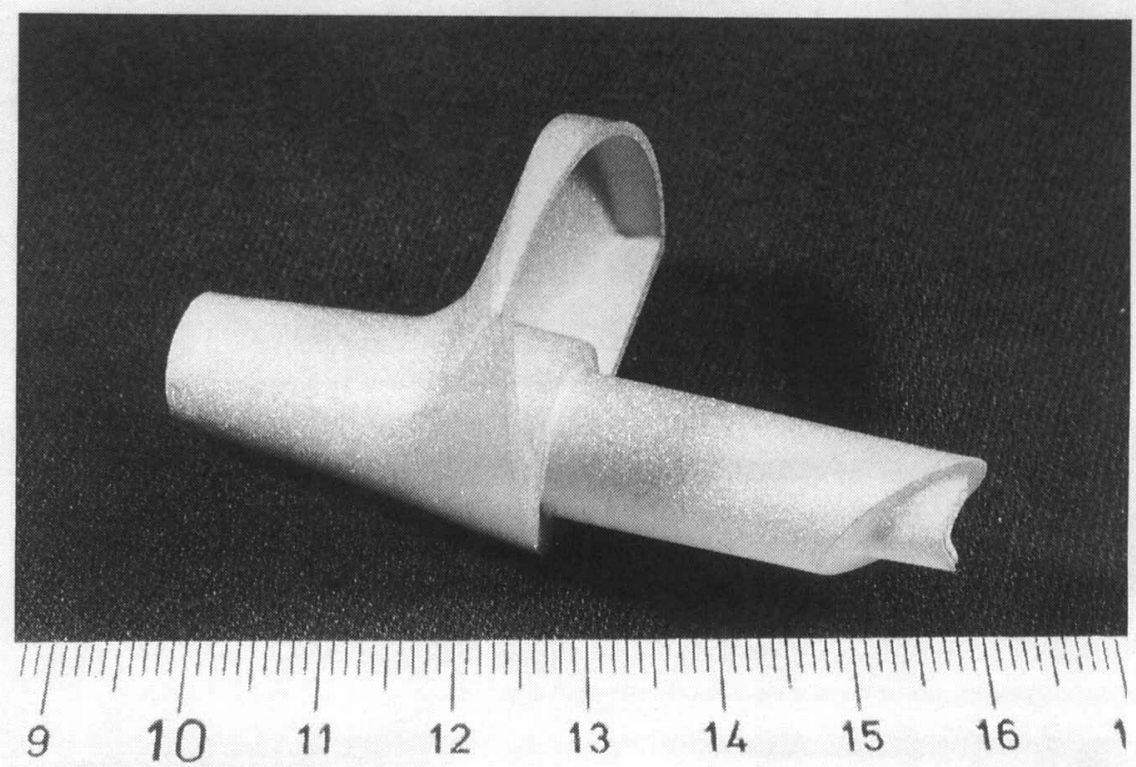

Fig.5 Typical pure Ti parts for practical use. 
3.6 Example of a part for practical use

Fig 5 shows an example of a pure Ti part that we produced for practical use. This example is HASSLE used for golf heads and it has a total length of $63 \mathrm{~mm}$, a cap with a radius of $25 \mathrm{~mm}$, and a weight of $28 \mathrm{~g}$.

\section{Conclusion}

The results obtained from this study can be summarized as follows:

(1) Utilizing gas atomized Ti powder that has low oxygen content, solvent extraction and high vacuum sintering makes production of Ti MIM parts possible.

(2) It is necessary to use a binder that provides good extraction by solvent. Using a binder with good extraction capability enables to control oxygen, nitrogen and carbon contents in the sintered compact as low as oxygen content of 0.22 mass $\%$, nitrogen content of 0.017 mass $\%$ and carbon content of 0.04 mass \%.

(3) The optimum sintering temperature is from 1443 to
$1463 \mathrm{~K}$.

(4) Mechanical properties of the sintered compact equivalent to those of Ti reactive material (Type JIS3) can be obtained.

\section{Acknowledgement}

We would like to thank Mr. Tadashi Ogasawara from SUMITOMO SITIX OF AMAGASAKI, INC. for this technical support during the chemical analysis in this study.

\section{References}

1) K.Kusaka, T.Kohno, T.Kondo and A.Horata: "Tensile Behavior of Sintered Titanium by MIM process", Journal of Japan Society of Powder and Powder Metallurgy, 42(1995)383-387.

2) T.Ieki, K.Katoh, A.Matsumoto, T.Masui and K.Andoh: "Tensile Properties of Sintered Ti Compacts by Metal Injection Molding Process", Journal of Japan Society of Powder and Powder Metallurgy, 44(1997)448-452. 